\title{
AC 2009-450: INTEGRATING CONCEPTS OF SUSTAINABLE AVIATION IN UNDERGRADUATE AEROSPACE ENGINEERING COURSES
}

Ramesh Agarwal, Washington University 


\title{
Integrating Concepts of Sustainable Aviation in Undergraduate Aerospace Engineering Courses
}

\begin{abstract}
The titles "Sustainable Aviation" or "Green Aviation" are recently being used with increasing frequency to address the technological and socioeconomic issues facing the aviation industry to meet the environmental challenges of twenty-first century. Air travel continues to experience the fastest growth among all modes of transportation. Therefore the environmental issues such as noise, emissions and fuel consumption, for both airplane and airport operations, have become important for energy and environmental sustainability. It is important therefore for the engineering students to become aware of these issues in an Introductory Course in Aeronautics. Some of the technology concepts currently being investigated by the industry for reducing noise, emissions and fuel consumption can be incorporated in appropriate existing courses in aerodynamics, aircraft structures, propulsion, guidance and control etc. at the undergraduate level. This paper provides some examples of inclusion of the sustainability ideas in aerodynamics and propulsion courses.
\end{abstract}

\section{Introduction}

In the next few decades, air travel is forecasted to experience the fastest relative growth among all modes of transportation, especially due to many fold increase in demand in major developing nations of Asia and Africa. Figure 1 shows the current market outlook for airplane demand by 2025 and Figure 2 shows various categories of 27,200 airplanes that would be needed by 2025 . The total value of new airplanes is estimated at $\$ 2.6$ trillion. As a result of three fold increase in air travel by 2025, it is estimated that the total $\mathrm{CO}_{2}$ emission due to commercial aviation may reach between 1.2 billion tonnes to 1.5 billion tonnes annually by 2025 from its current level of 670 million tonnes. The amount of nitrogen oxides around airports, generated by aircraft engines, may rise from 2.5 million tonnes in 2000 to 6.1 million tonnes by 2025. The number of people who may be seriously affected by aircraft noise may rise from 24 million in 2000 to 30.5 million by 2025. Therefore there is urgency to address the problems of emissions and noise abatement through technological innovations in design and operations of the commercial aircraft. Aerospace International, published by the Royal Aeronautical Society of U.K., has identified 25 new technologies, initiatives and operational improvements that may make air travel one of the greenest industries by 2050 [1]. These 25 green technologies/concept areas are listed below from Reference [1].

1) Biofuels - These are already showing promise; the third generation biofuels may exploit fast growing algae to provide a drop-in fuel substitute.

2) Advanced composites - The future composites will be lighter and stronger than the present composites which the airplane manufacturers are just learning to work with and use. 
3) Fuel cells - Hydrogen fuel cells will eventually take over from jet turbine Auxiliary Power Units (APU) and allow electrics such as in-flight entertainment (IFE) systems, galleys etc. to run on green power.

4) Wireless cabins - The use of Wi-Fi for IFE systems will save weight by cutting wiring - leading to lighter aircraft.

5) Recycling - Initiatives are now underway to recycle up to $85 \%$ of an aircraft's components, including composites - rather than the current $60 \%$. By 2050 this could be at $95 \%$.

6) Geared Turbofans (GTF) - Already under testing, GTF could prove to be even more efficient than predicted, with an advanced GTF providing $20 \%$ improvement in fuel efficiency over today's engines.

7) Blended wing body aircraft - These flying wing designs would produce aircraft with increased internal volume and superb flying efficiency, with a 20-30\% improvement over current aircraft.

8) Microwave dissipation of contrails - Using heating condensation behind the aircraft could prevent or reduce contrails formation which leads to cirrus clouds.

9) Hydrogen-powered aircraft - By 2050 early versions of hydrogen powered aircraft may be in service - and if the hydrogen is produced by clean power, it could be the ultimate green fuel.

10) Laminar flow wings - It has been the goal of aerodynamicists for many decades to design laminar flow wings; new advances in materials or suction technology will allow new aircraft to exploit this highly efficient concept.

11) Advanced air navigation - Future ATC/ATM systems based on Galileo or advanced GPS, along with international co-operation on airspace, will allow more aircraft to share the same sky, reducing delays and saving fuel.

12) Metal composites - New metal composites could result in lighter and stronger components for key areas.

13) Close formation flying - Using GPS systems to fly close together allows airliners to exploit the same technique as migrating bird flocks, using the slip-stream to save energy.

14) Quiet aircraft - Research by Cambridge University and MIT has shown that an airliner with imperceptible noise profile is possible - opening up airport development and growth. 
15) Open-rotor engines - The development of the open-rotor engines could promise $30 \%+$ breakthrough in fuel efficiency compared to current designs. By 2050, coupled with new airplane configurations, this could result in a total saving of $50 \%$.

16) Electric-powered aircraft - Electric battery-powered aircraft such as UAVs are already in service. As battery power improves one can expect to see batteries powered light aircraft and small helicopters as well.

17) Outboard horizontal stabilizers $(\mathrm{OHS})$ configurations - OHS designs, by placing the horizontal stabilizers on rear-facing booms from the wingtips, increase lift and reduce drag.

18) Solar-powered aircraft - After UAV applications and the Solar Impulse round the world attempt, solar-powered aircraft could be practical for light sport, motor gliders, or day-VFR aircraft. Additionally, solar panels built into the upper surfaces of a BlendedWing-Body (BWB) could provide additional power for systems.

19) Air-to-air refueling of airliners - Using short range airliners on long-haul routes, with automated air-to-air refueling could save up to $45 \%$ in fuel efficiency.

20) Morphing aircraft - Already being researched for UAVs, morphing aircraft that adapt to every phase of flight could promise greater efficiency.

21) Electric/hybrid ground vehicles - Use of electric, hybrid or hydrogen powered ground support vehicles at airports will reduce the carbon footprint and improve local air quality.

22) Multi-modal airports - Future airports will connect passengers seamlessly and quickly with other destinations, by rail, Maglev or water, encouraging them to leave cars at home.

23) Sustainable power for airports - Green airports of 2050 could draw their energy needs from wave, tidal, thermal, wind or solar power sources.

24) Greener helicopters - Research into diesel powered helicopters could cut fuel consumption by $40 \%$, while advances in blade design will cut the noise.

25) The return of the airship - Taking the slow route in a solar-powered airship could be an ultra 'green' way of travel and carve out a new travel niche in 'aerial cruises', without harming the planet.

It is therefore time now to introduce the undergraduate and graduate students in Mechanical, Aerospace, and related relevant engineering disciplines to these green technologies and concepts, and include some of the technologies and concepts in the existing courses in aerodynamics, propulsion, structures, guidance and control etc. as appropriate to modernize the contents of the curriculum. In some cases it may be necessary to introduce altogether new courses. 


\section{Current Market Outlook}

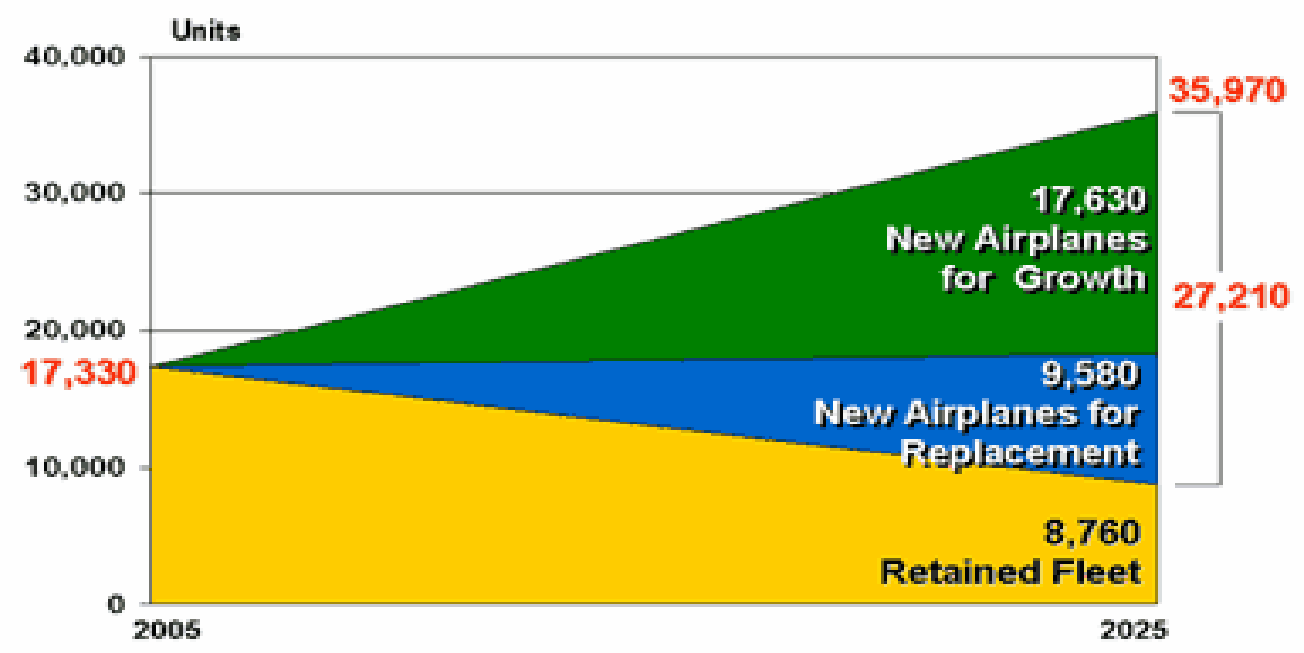

Figure 1: Market Forecast for New Airplanes

(http://www.boeing.com/randy/archives/2006/07/in_the_year_202.html)

\section{7 \& larger}

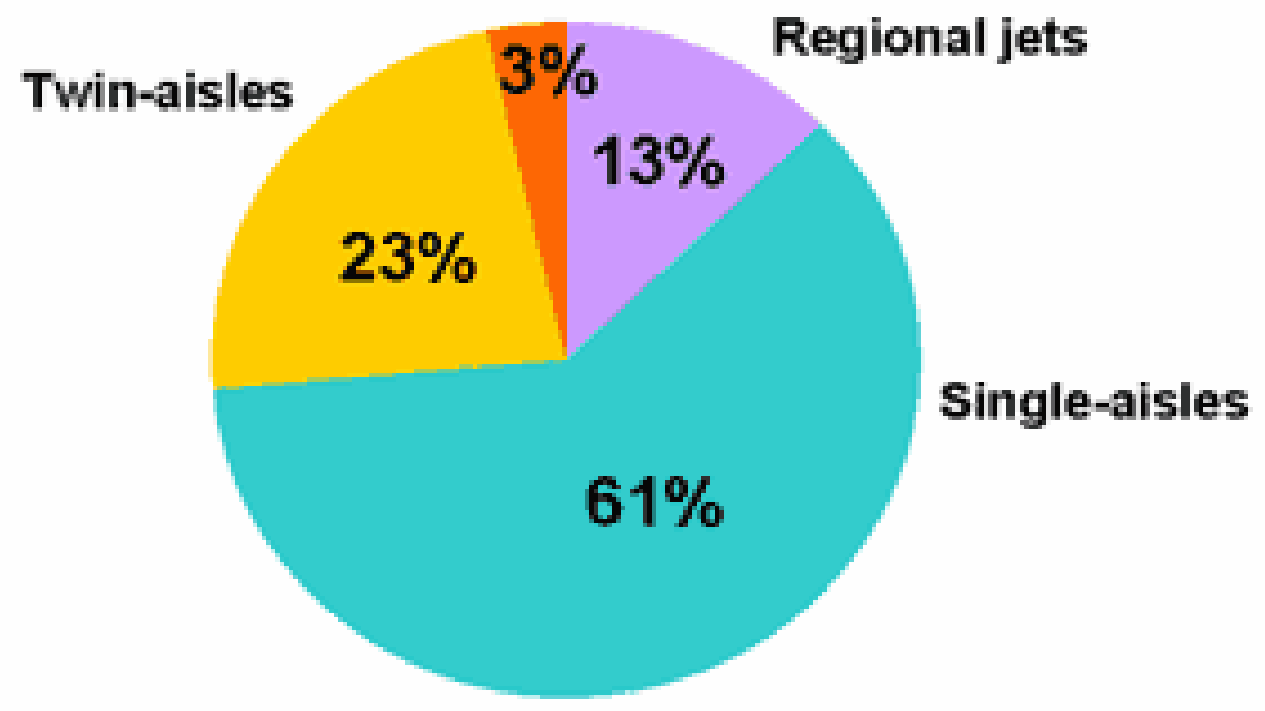

27,200 new airplanes

\$2.6 trillion delivery dollars

Figure 2: Demand Forecast for Various Type of Airplanes by 2025

(http://www.boeing.com/randy/archives/2006/07/in_the_year_202.html) 


\section{Incorporation of Green Technologies in Aeronautical Courses}

At Washington University in St. Louis, we offer six aeronautical engineering courses as part of the undergraduate "Aerospace Minor" in the department of Mechanical, Aerospace and Structural Engineering (MASE). These courses are: MASE 2701 Introduction to Aerospace Vehicles, MASE 5700 - Aerodynamics, MASE 5701 Aerospace Propulsion, MASE 4302 - Aircraft Stability and Control, MASE 321 Structural Behavior and Analysis, and MASE 411 - Mechanical/Aerospace Design. Initially we are planning to incorporate the concepts of aviation sustainability and green technologies in three of the aeronautical courses, namely Introduction to Aerospace Vehicles, Aerodynamics, and Aerospace Propulsion. We intend to include about three to five lectures, each of one hour duration to begin with, at appropriate places in the syllabus. The idea is not to compromise the core content of the course but to supplement it with ideas of sustainability.

At this stage, some of the ideas of sustainability mentioned in the 'Introduction' have been introduced in only two of the courses taught by the author, i.e. MASE 5700 Aerodynamics and MASE 341 - Fluid Mechanics. The student response has been excellent. We plan to introduce additional concepts on green technologies in other courses in the near future. In the Aerodynamics course, the concepts of drag reduction using active flow control and laminar flow wing are explained in the context of fuel savings and in turn in reducing the emissions. The design and performance of Honda Jet (Figure 3), which has natural laminar flow wings is compared with other conventional wing aircrafts in fuel efficiency. The basic concepts behind the newly emerging aircraft designs/configurations such as Blended -Wing -Body (Figure 4), Silent Aircraft (Figure 5), Hydrogen Power Aircraft (Figure 6), Solar Power Aircraft (Figure 7), and Electric Aircraft (Figure 8) are introduced as ways of reducing noise and emissions. One can design aircrafts which can be fuel efficient and reduce emissions as shown in Figure 9 [2 -4]. Many researchers are working in the area of sustainable aircraft design [2 -7]. We intend to introduce these ideas in the aerospace design course. It should be noted that the scope and one semester duration of the course do not allow for any detailed discussions of the aerodynamics of these emerging aircraft designs/configurations. The purpose is to bring to the attention of the students what is happening in industry and government to make the aviation 'greener' and what are the basic aerodynamic concepts that can be used in designing more fuel efficient aircraft.

In the course on Aerospace propulsion, the concepts of high bypass engines and geared turbofans for improved efficiency are introduced. The plan is to introduce alternative technologies such as fuel cells, solar power and hydrogen for propulsion. The alternative fuels such as biofuels and syngas fuels which have reduced emissions compared to currently used jet fuels will also be introduced. Figure 10 shows alternative fuels for improved efficiency and reduced emissions [4]. Figure 11 shows the effect of flying altitude on emissions [2-4]. The use of chevron nozzles can reduce noise as well as special flight paths can change the directivity of noise near airports to help mitigate its effect on people living near airports. These ideas are brought to focus in this course. 
In the Introductory course on Aerospace Engineering, the issues of environmental challenges such as noise and emissions will be introduced in the context of current status and projected increase in noise and emissions in next twenty five years due to three fold increase in air travel (and as a result two fold increase in flying aircraft). If no new technologies are introduced and status-quo is allowed to remain, the aircraft emissions will contribute about $17-20 \%$ to total equivalent $\mathrm{CO}_{2}$ emissions from all sources worldwide, which will not be acceptable because of worldwide efforts to reduce greenhouse gas (GHG) emissions due to their adverse impact on climate.

We are also planning to introduce other green aviation technologies mentioned in the 'Introduction' in courses in Aircraft Structures and Aircraft Flight Dynamics and Control. It is anticipated that in a couple years, many of the "green aviation' concepts listed in the 'Introduction' will become a part of the aerospace courses. Based on the students' feedback, the material covered will be improved and changed. It should be noted that the core contents/syllabus of these courses will not significantly change by introducing the sustainability concepts.

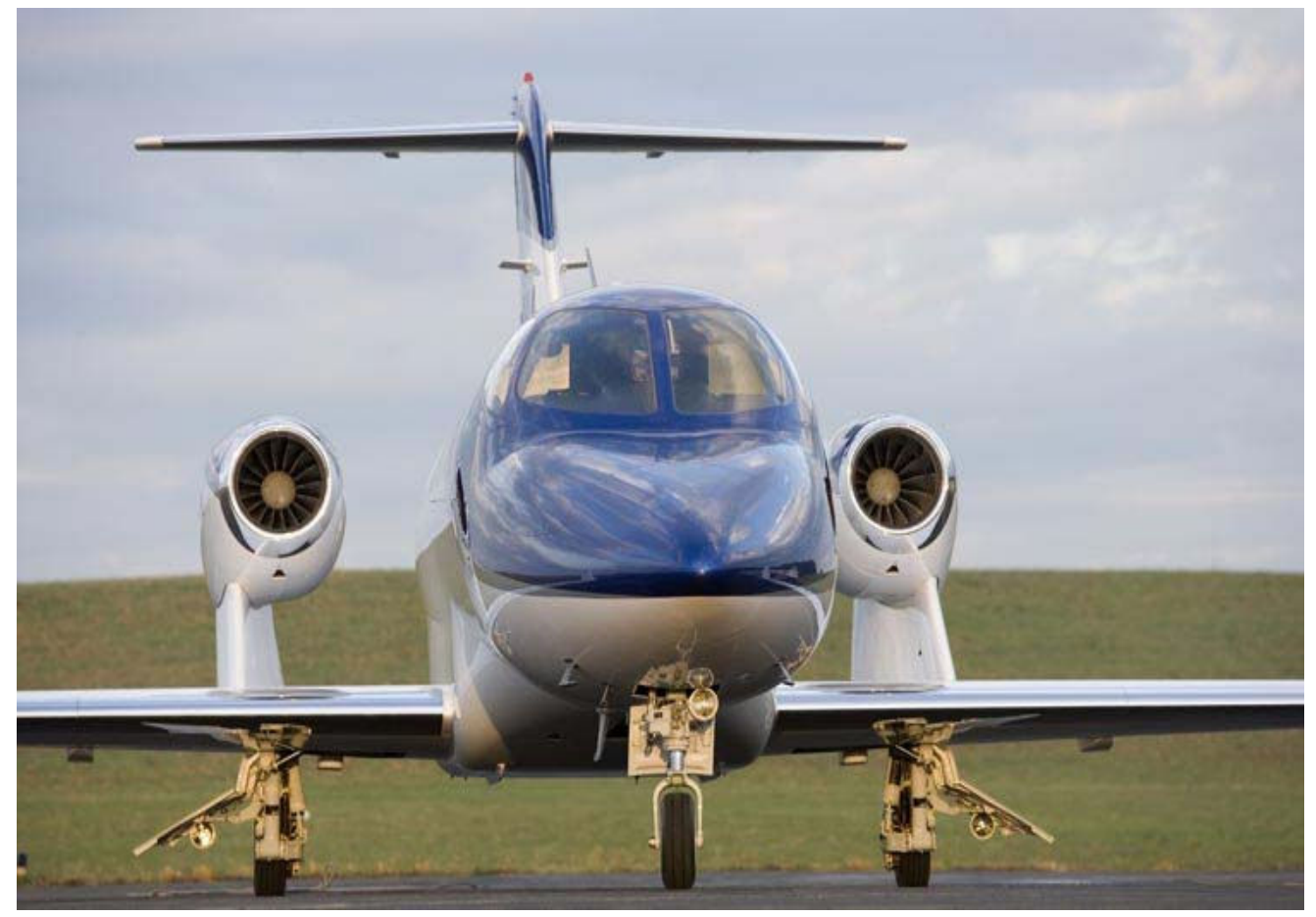

Figure 3: Honda Jet: A combination of Over the Wing (OTW) engine mount design, Natural Laminar Flow Wing (NLF), all Composite Fuselage, HF - 120 Turbofan Engine gives it a 30-35\% more fuel efficiency and higher cruise speed than conventional light business jets (http://hondajet.honda.com) 


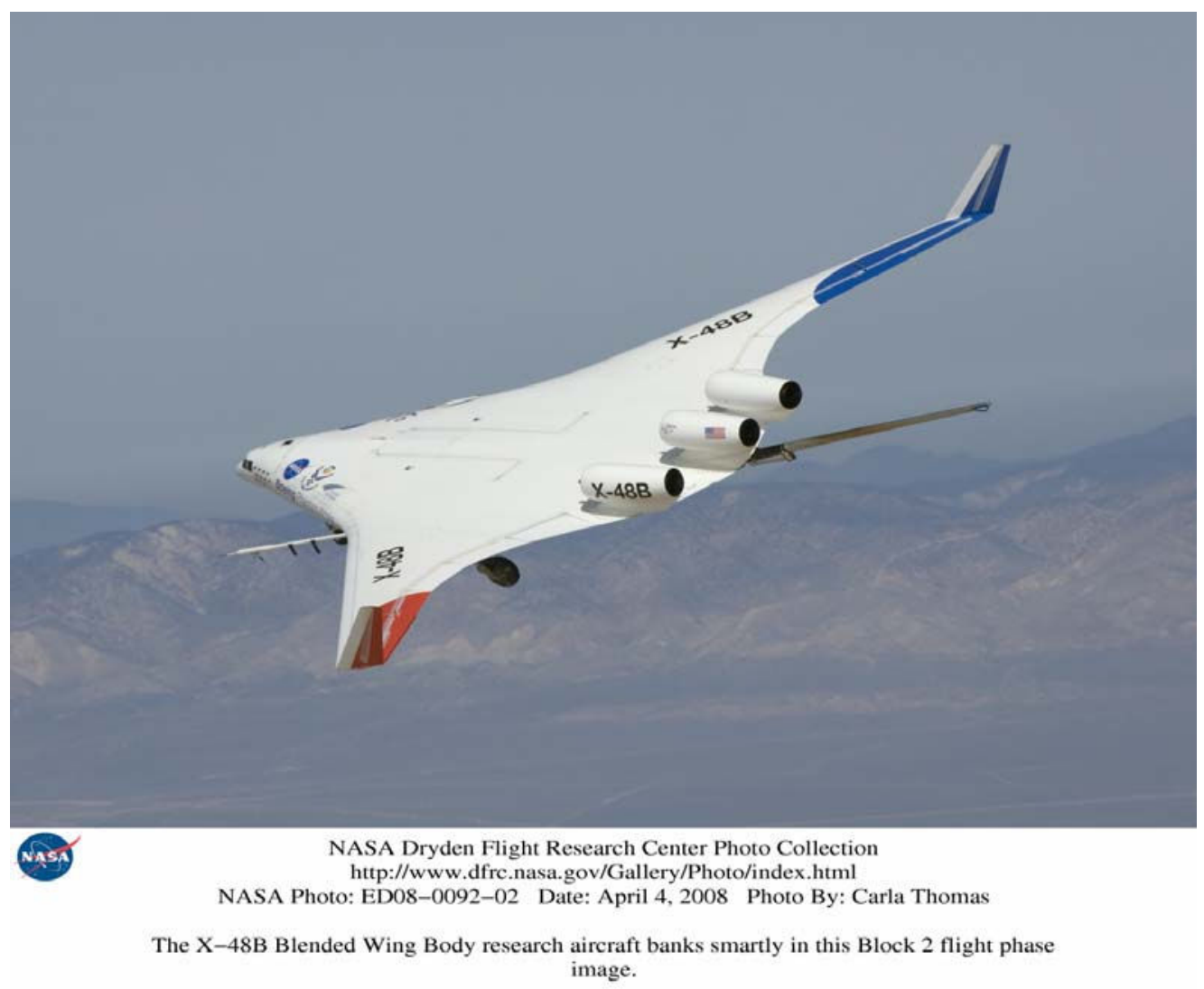

Figure 4: Blended-Wing-Body (BWB): Flying wing concept based aircraft design with high subsonic cruise speeds and range of $7000 \mathrm{~nm}$, requires $20 \%$ less fuel than conventional aircraft designs (http://www.dfrc.nasa.gov/Gallery/Photo/X48B/index.html)

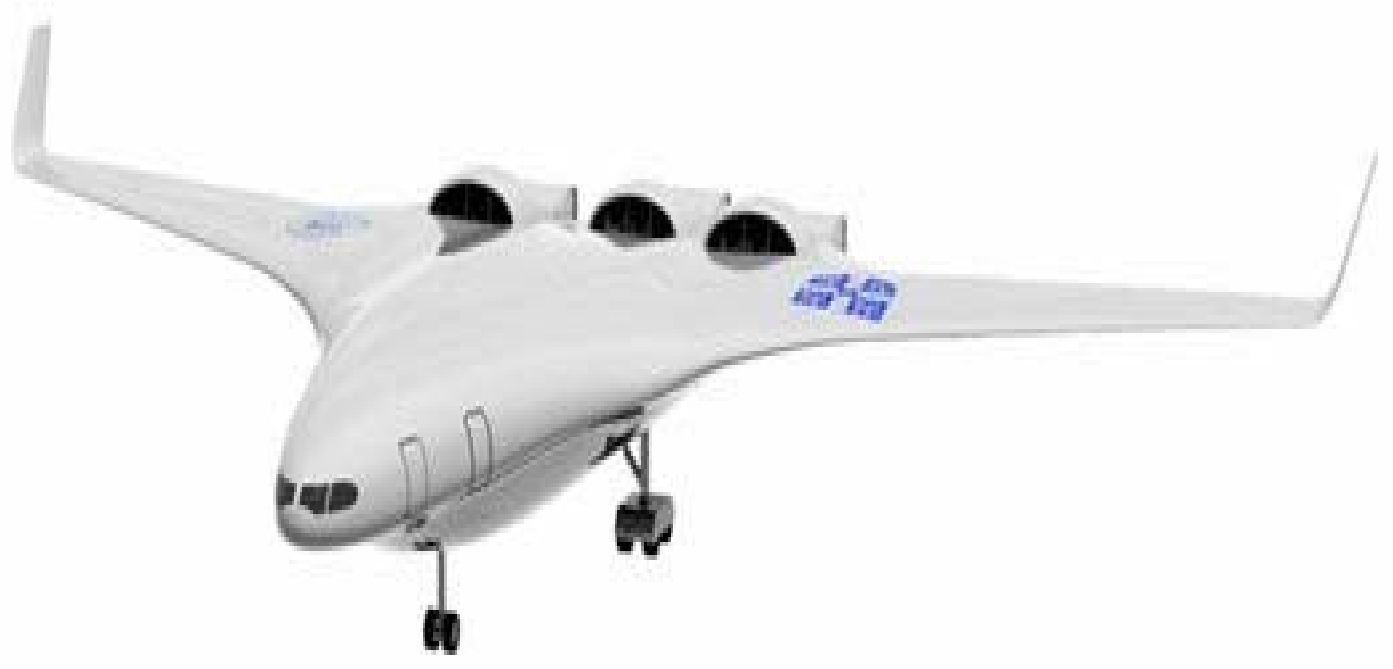

Figure 5: Silent Aircraft: A joint MIT - Cambridge University design with innovative Aircraft/Engine design that has imperceptible noise outside an urban airport (http://silentaircraft.org/) 
Advantages:

- Reduced emissions

- Lower takeoff weight

- Better long haul fuel efficiency

- Engine design opportunities

- Oil independent fuel?

- $\mathrm{H}_{2}$ works well with fuel cells

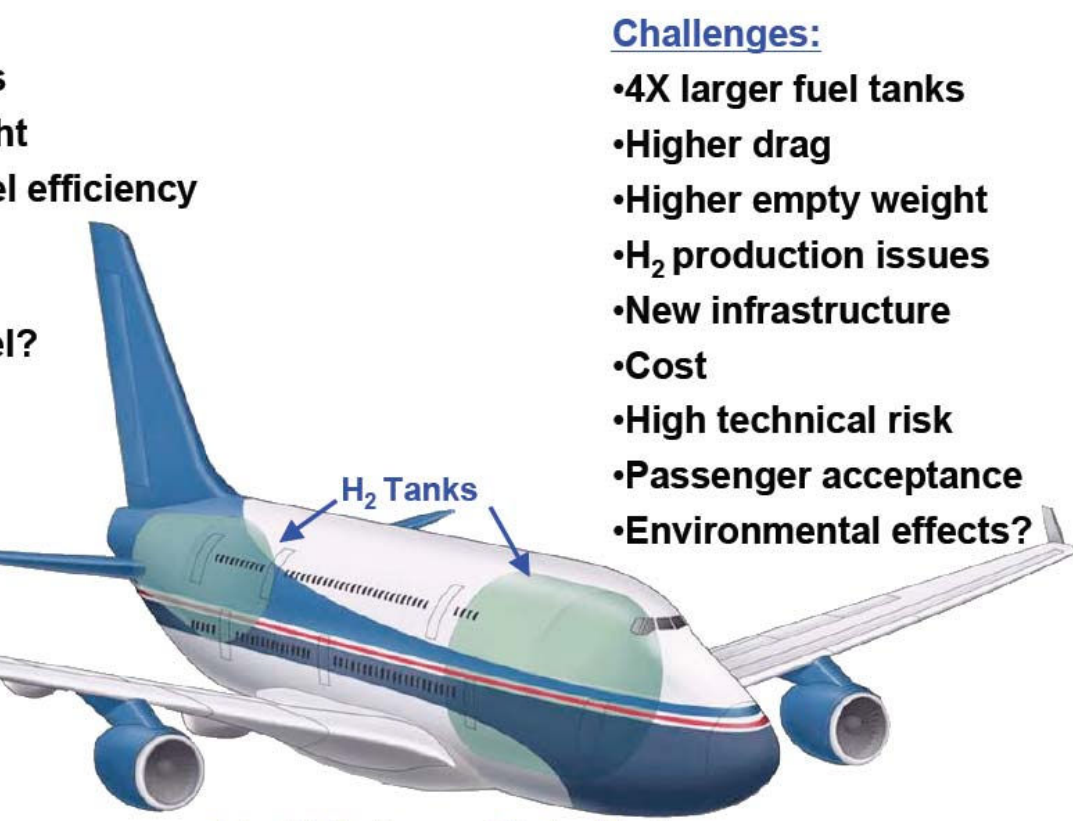

Liquid Hydrogen Study Airplane

Figure 6: Hydrogen Powered Aircraft: Advantages and Challenges [4]

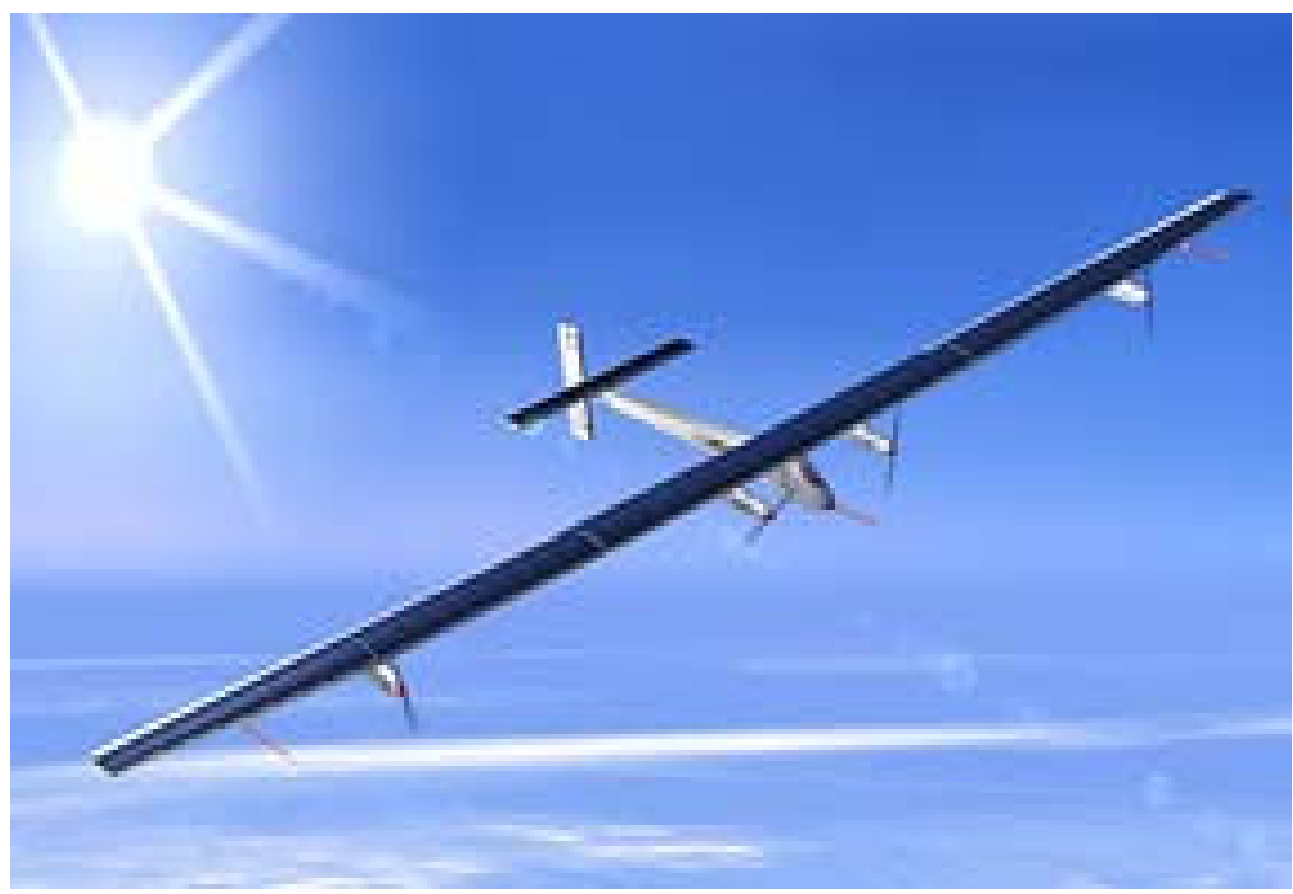

Figure 7: Solar Power Aircraft Design from SOLARIMPULSE

(www.solarimpulse.com) 


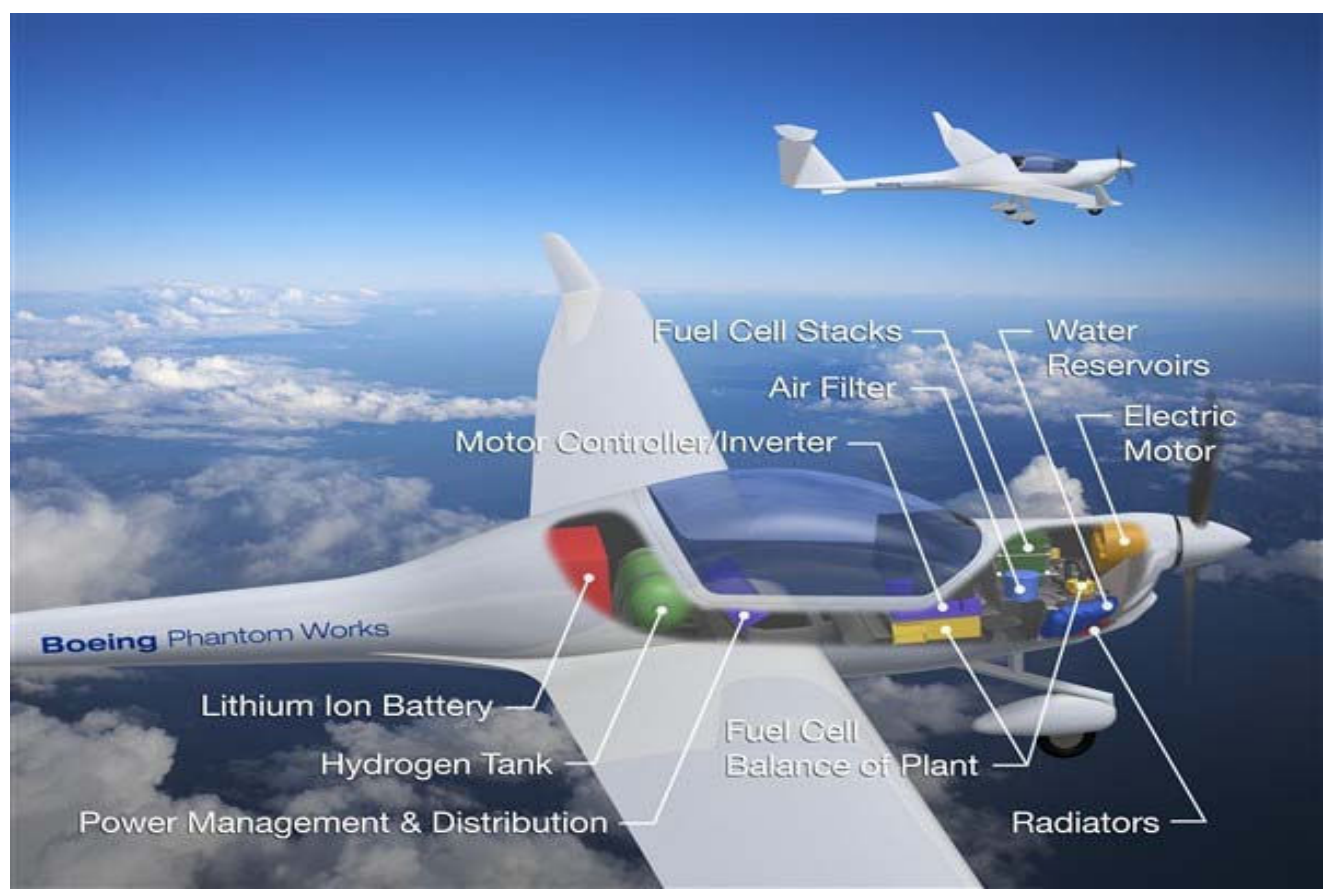

Figure 8: Boeing PEM Fuel Cell Powered Electric Aircraft (www.boeing.com)
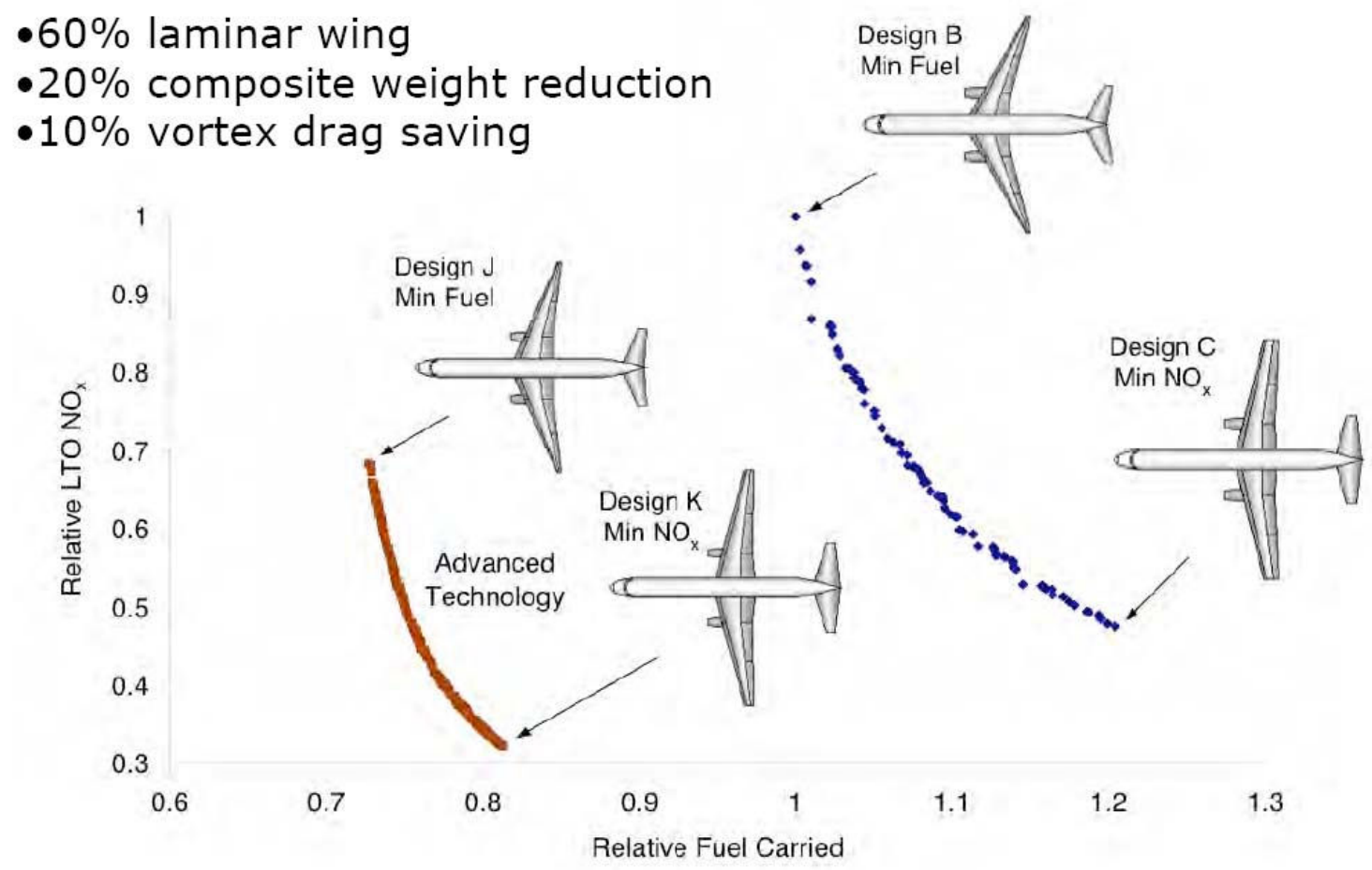

Figure 9: Benefits of increased laminar flow, reduced induced drag and lower structural weight on the fuel cost and emissions [2 -4] 

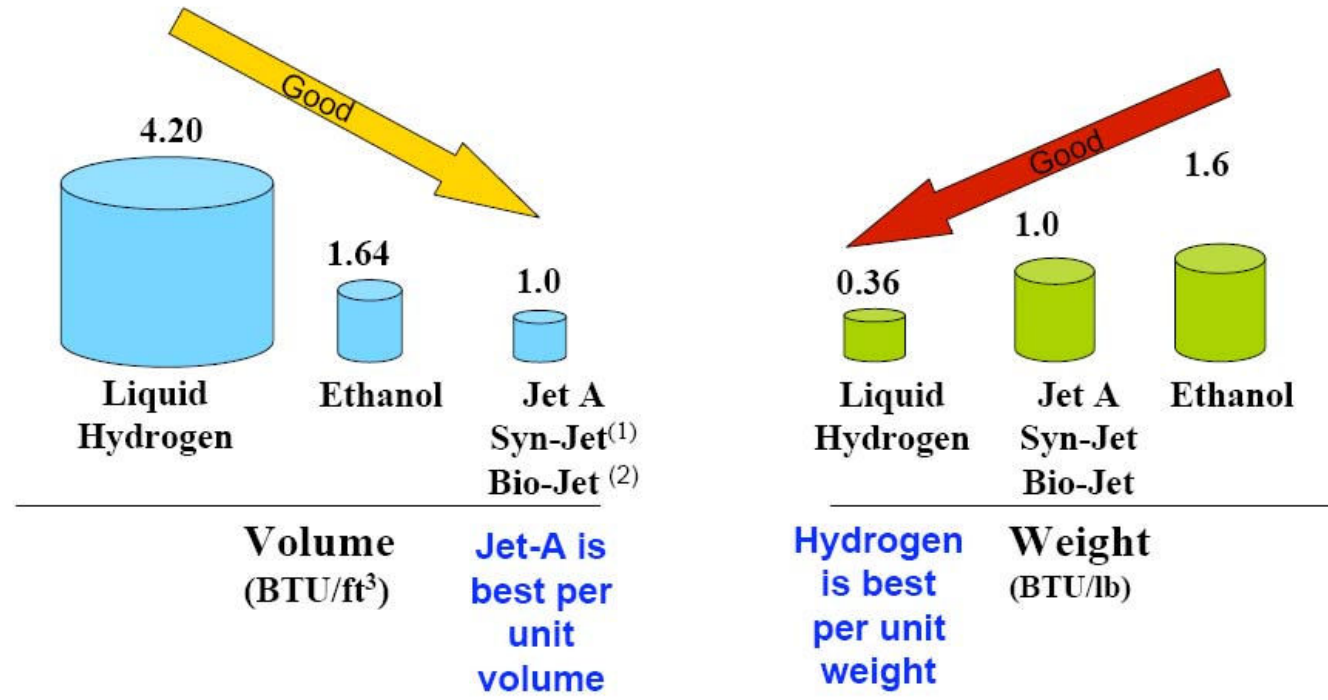

Hydrogen Weight

is best (BTU/lb)

per unit

weight

\section{*Equivalent Energy}

(1) Synthetic Jet fuel such as from Fisher-Tropsch process

(2) Bio-derived jet fuel similar to a refined bio-diesel fuel

Figure 10: Volume and weight comparisons of alternative fuels for aviation for same amount of energy [4]

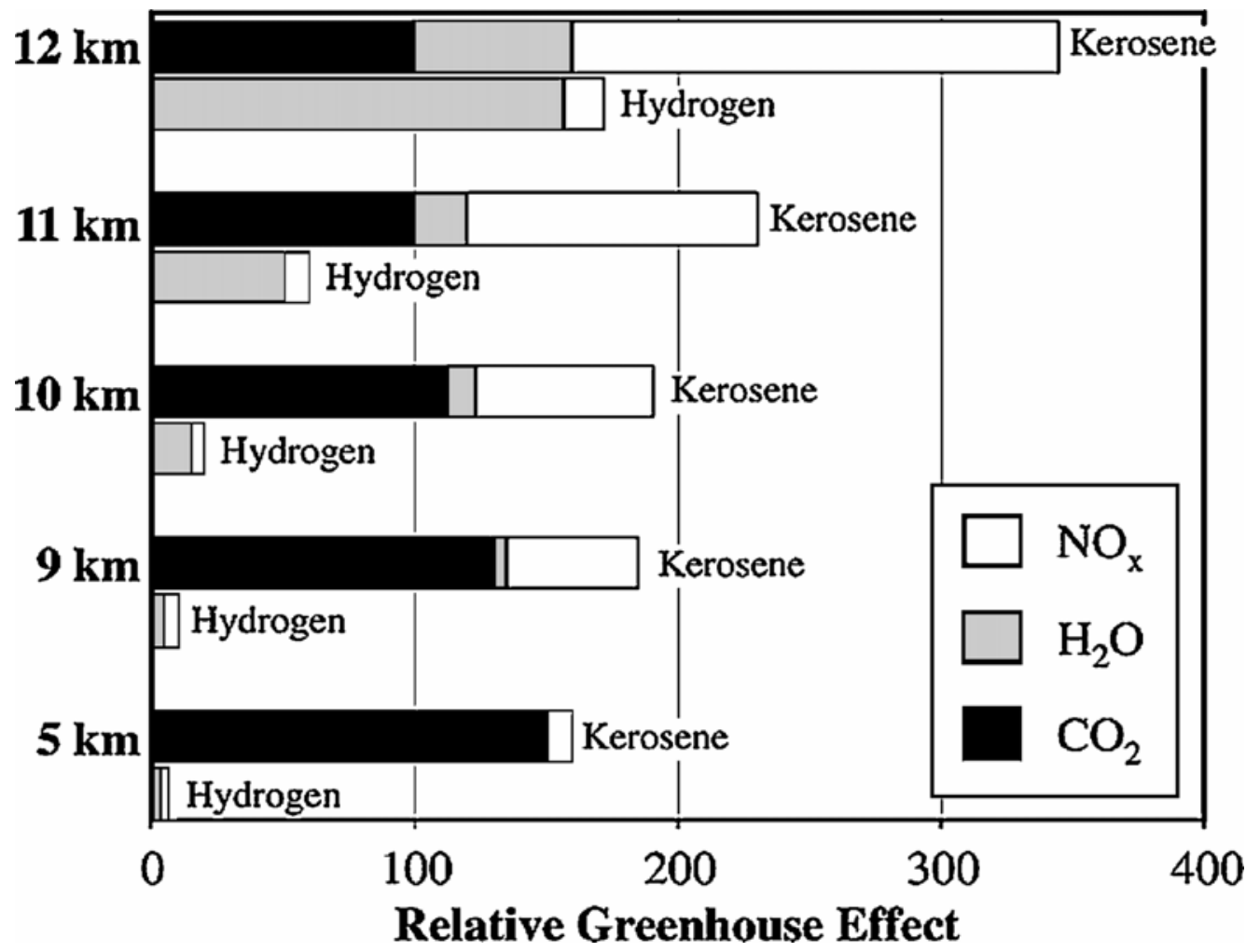

Figure 11: Effect of fuel type and cruise altitude on net greenhouse effects [2 -4] 


\section{Conclusions}

It is increasingly recognized that the concepts of sustainability should be introduced in engineering curriculum. Among many facets of sustainability, environmental sustainability has become one of the most important topics because of its direct impact on human health and welfare, and climate change. In this paper, we have tried to show how some of the environmental sustainability ideas can be introduced in the existing undergraduate aerospace engineering courses without changing the core content of the courses. We will be reporting our experience in this area in future ASEE conferences which may be beneficial to other engineering schools as they contemplate introducing sustainability in the curriculum.

\section{References}

1. Aerospace International, March 2009, The Green Issue, Aerosociety, U.K.

2. Antoine, N. E., "Aircraft Optimization for Minimal Environmental Impact," Ph.D. Dissertation, Dept. of Aeronautics and Astronautics, Stanford University, Sept. 2004.

3. Antoine, N. E. and Kroo, I. M., "Framework for Aircraft Conceptual Design and Environmental Performance Studies,” AIAA J., Vol. 43, 2005, pp. 2100-2109.

4. Kroo, I. M., "Sustainable Aviation: Future Air Transportation and the Environment," Presentation at 50th Anniversary Celebration, Dept. of Aeronautics and Astronautics, Stanford University, May 2008.

5. Schwartz, E. and Kroo, I. M., "Aircraft Design: Trading Cost and Climate Impact," AIAA Paper 2009-1261, 47th Aerospace Sciences Meeting, Orlando, FL, 5-8 January 2009.

6. Vera-Morales, M. and Hall, C. A., "Modeling Performance and Emissions from Aircraft for the Aviation Integrated Modeling Project," AIAA Paper 2009-1263, 47th Aerospace Sciences Meeting, Orlando, FL, 5-8 January 2009.

7. Filippone, A., "Analysis of Carbon-Dioxide Emissions from Transport Aircraft," J. of Aircraft, Vol. 45, 2008, pp. 185-197. 